\title{
A system's approach to assess the exposure of agricultural production to climate change and variability
}

\author{
Aavudai Anandhi ${ }^{1,2} \cdot$ Jean L. Steiner ${ }^{2}$. \\ Nathaniel Bailey ${ }^{1}$
}

Received: 3 June 2015 / Accepted: 21 February 2016 /Published online: 23 April 2016

(C) The Author(s) 2016. This article is published with open access at Springerlink.com

\begin{abstract}
Estimating the exposure of agriculture to climate variability and change can help us understand key vulnerabilities and improve adaptive capacity, which is vital to secure and increase world food production to feed its growing population. A number of indices to estimate exposure are available in literature. However, testing or validating them is difficult and reveals a considerable variability, and no systematic methodology has been developed to guide users in selecting indices for particular applications. This need is addressed in this paper by developing a flowchart from a conceptual model that uses a system's approach. Also, we compare five approaches to estimate exposure indices (EIs) to study the exposure of agriculture to climate variability and change: single stressor-mean climate, single stressor-extreme climate, multiple stressor-mean climate, multiple stressor-extreme climate; and combinations of the above approaches. The developed flowchart requires gathering information on the region of study, including its agriculture, stressor(s), climate factor(s) $(C F)$, period of interest and the method of aggregation. The flowchart was applied to a case study in Kansas to better understand the five approaches to estimate $E I$ s and the implications of the choices made in each step on the estimated the exposure. The flowchart provides options that guide $E I$ estimation by selecting the most appropriate stressor(s), associated $C F(\mathrm{~s})$, and aggregation methods when a detailed methodological analysis is possible, or proposes a default method when data or resources do not allow a detailed analysis. Climate adaptation involves integration of a multitude of factors across complex systems. A more standardized approach to
\end{abstract}

Electronic supplementary material The online version of this article (doi:10.1007/s10584-016-1636-y) contains supplementary material, which is available to authorized users.

Aavudai Anandhi

anandhi@famu.edu

1 Biological and Agricultural Systems Engineering, Florida Agricultural and Mechanical University, Tallahassee, FL 32307, USA

2 US Department of Agriculture, Agricultural Research Service, Grazinglands Research Laboratory, 7207 West Cheyenne Street, El Reno, OK 73036, USA 
assessing exposure can promote information sharing across different locations and systems as this rapidly evolving area of study moves forward.

\section{Introduction}

The emerging consensus is that the world likely will exceed 9 billion people by 2050 and is unlikely to stabilize in the 21 st century (Gerland et al. 2014), requiring 70-100\% more food production (Tscharntke et al. 2012). Even the most optimistic scenarios require at least a $50 \%$ increase in food production (Horlings and Marsden 2011). Threats posed by climate variability and extremes to land and water resources are heightening the challenge of increasing food production (Horlings and Marsden 2011). As the projected degree and pace of climate change accelerates, exacerbed by other biophysical limits such as declining per-capita land and water and rising demand for agricultural products, the need for a systemic, powerful adaptation of agriculture to variable and changing conditions is increasingly obvious (Rickards and Howden 2012). Climate change presents unprecedented challenges to the adaptive capacity of agriculture by influencing crop distribution and production and by increasing the economic and environmental risks associated with a multitude of agricultural systems (Walthall 2012).

Much of the current understanding of adaptive capacity to climate stressors comes from vulnerability assessments (Adger et al. 2007). The vulnerability of a system to climate change is characterized in the earlier IPCC report (McCarthy et al, 2001) as a function of three dimensions: the exposure, sensitivity and adaptive capacity of the system (Antwi-Agye et al. 2012). McCarthy et al. (2001) defined exposure as the "degree of climate stress upon a particular unit of analysis". The vulnerability of an agricultural system to climate change is dependent in part on the character, magnitude, and rate of climate variation to which a system is exposed (Walthall 2012). Hence, exposure to adverse climatic conditions is an important aspect of agricultural vulnerability (Jackson et al. 2012). In a recent Intergovernmental Panel for Climate Change report (IPCC-AR5), exposure is determined to be an important precondition for considering a specific vulnerability as key. This is because if a system is not at present nor in the future exposed to hazardous climatic trends or events, its vulnerability to such hazards is not relevant (Oppenheimer et al. 2014). Thus, estimating the exposure of agriculture to climate change will help us understand a region's key vulnerabilities and improve its adaptive capacity, which is important for increasing food production to meet growing world demand.

The objectives of this study are to (1) compare five conventional approaches used to study the exposure of agriculture to climate change, (2) develop a systems approach to summarize in a flowchart the steps and the most relevant processes and information that should be taken into account to estimate the exposure of agriculture to climate change -, and (3) present a case study to illustrate the implications of the choices made in the steps of the flowchart and the different approaches to estimate EIs.

\section{Methods for estimating exposure}

\subsection{Definitions of exposure in relation to climate}

The definitions that systematize exposure in the context of climate change and variability are multiple, overlapping, and evolving (Oppenheimer et al. 2014) as summarized in supplementary 
material (S.1). In this study, the general definition of exposure is tailored for agricultural production: the presence of agro-ecosystems in settings that could be adversely affected by climate stress due to climate variability arising from mean and extreme events affecting agriculture production.

\subsection{Review of exposure methods: index-based approaches}

A number of methods are available in the literature to estimate exposure and can be classified as econometric methods or indices. Econometric methods use socioeconomic survey data based on questionnaires, whereas an index is calculated using one or more indicators (Deressa et al. 2008). An index-based approach is the focus of this study because 1) indices are powerful tools to communicate technical data in relatively simple terms which portray the interrelationships among climate and other physical and biological elements of the environment to help reveal evidence of the discernible impacts of climate change (Kadir et al. 2013); 2) much of the current understanding of exposure of agriculture to climate change comes from vulnerability assessments based on indices; 3) indices often provide important insights on the factors, processes, and structures that promote or constrain adaptive capacity; 4) the index-based approach is valuable for monitoring trends and exploring conceptual frameworks (Luers et al. 2003; Deressa et al. 2008); and 5) indices have often been used to estimate exposure in agriculture (Luers et al. 2003; Simelton et al. 2009; Challinor et al. 2010; Antwi-Agyei et al. 2012) and is aligned to areas including water resources (Babel et al. 2011) and ecosystems (Fraser et al. 2003).

In this paper, exposure index $(E I)$ refers to the indices calculated to represent the exposure of agriculture to climate change and variability. Stressors refer to events/variables/natural hazards that stress agriculture, including extreme temperature, drought, floods, landslides, or sea-level rise. Climate factors (CFs) refer to variables (e.g., crop failure temperature) or statistics (e.g., standard precipitation index, coefficient of variation in rainfall) that are calculated to represent one or more stressors.

Numerous EIs are available throughout the literature to estimate exposure of agriculture to climate change and variability (Table S.1). In summary, Table S.1 shows that EIs are also referred to as a drought index (Simelton et al. 2009; Challinor et al. 2010), climate change index (Baettig et al. 2007), hazard EI (Anh 2011), and climate vulnerability index (Jackson et al. 2012).

This study identified exposure assessments are available for many regions in different parts of the world (China, Ethiopia, Ghana, India, South America, Tajikistan, USA), indicating gaps in some regions (e.g., temperate and boreal regions). Common characteristics in the exposure assessments include: They 1) are estimated for a range of spatial scales from household to regional to global (O'Brien et al. 2004a; O'Brien et al. 2004b; Baettig et al. 2007; Challinor et al. 2010; Fraser et al. 2013); 2) are estimated for a variety of crops; 3 ) use a $C F$ to represent a stressor; 4) are calculated using data from multiple sources, such as measured data (Simelton et al. 2009; Heltberg and Bonch-Osmolovskiy 2011; Antwi-Agyei et al. 2012), modeled data (O'Brien et al. 2004b; Baettig et al. 2007; Gbetibouo et al. 2010), survey data (Pandey and Jha 2012), satellite remote-sensing products (Dong et al. 2012), maps (Anh 2011), and/or earlier studies (Bhattacharya and Das 2007); 5) are estimated at multiple time periods such as past, present, and/or future -(O’Brien et al. 2004a; Simelton et al. 2009; Antwi-Agyei et al. 2012; Fraser et al. 2013); and 6) require an aggregation method when multiple $C F$ s are used (Table S.1b). These characteristics are arranged in steps and used in the development of the flowchart to estimate $E I$. 
Issues and challenges in calculating EI include: a) no systematic methodology has been developed to operationalize the stressors (O'Brien et al. 2004b), b) testing or validating the different EIs involves considerable subjectivity and difficulty (Luers et al. 2003; Deressa et al. 2008), and c) the implications of using single/multiple stressor(s), single/multiple $C F(\mathrm{~s})$ or combinations on the estimated $E I$ have not been addressed in detail in the literature. To address this need a flowchart is developed in this study using the systems framework (Fig. 1b and c) to estimate EI. The flowchart is comprised of six steps and uses regional characteristics such as: type of agriculture or landuse; stressor(s); climate factor $(C F)$; time period of interest; and the method of aggregation.

\subsection{Summary of index-based approaches}

The various EIs in Table S.1 can be summarized by classifying them into five conventional approaches. In approach 1: single stressor - mean climate, the $E I$ is calculated from a single stressor and single/multiple $C F \mathrm{~s}$. The $C F$ s describe the mean climate of the stressor. In approach 2: single stressor - extreme climate, the $E I$ is also calculated from a single stressor and single/ multiple $C F \mathrm{~s}$, but unlike in approach 1 , the $C F \mathrm{~s}$ describe the extreme climate of the stressor. In approach 3, multiple stressors - mean climate, the $E I$ is calculated from multiple stressors, and each stressor is represented using single/multiple $C F$ s that describe the mean climate. In approach 4, the $E I$ is calculated from multiple stressors, and each stressor is represented using single/

(a)

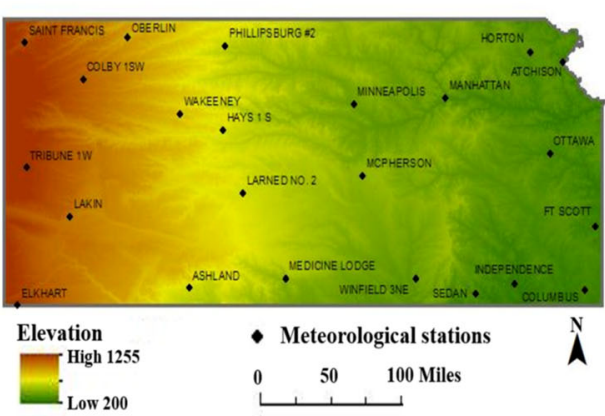

(c)

(b)

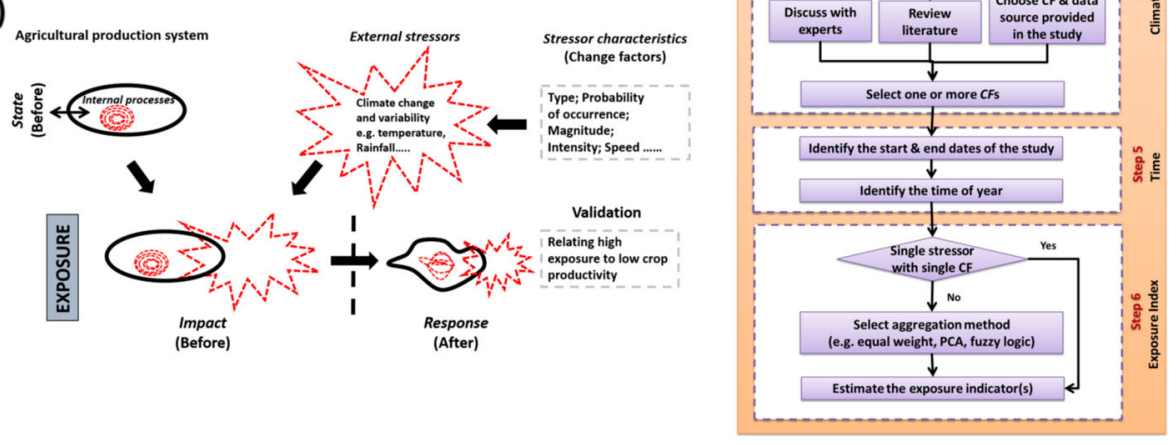

Fig. 1 a Location map of the meteorological stations used in Kansas. b Conceptual framfork using systems approach to estimate exposure of agricultural production to climate change and variability (c) Flowchart to estimate Exposure Index $(E I)$ to represent the exposure of agriculture to climate variability and change. $\mathrm{CF}$ in the figure refers to climate factors; PCA refer to principal component analysis 
multiple $C F \mathrm{~s}$ that describe extreme climate. Approach 5 is a combination approach in which $C F \mathrm{~s}$ can describe both mean and extreme climate and can represent single or multiple stressors.

An $E I$ estimated using approaches 1 to 5 can be calculated using Eq. 1.

$$
E I_{i}=\frac{\text { Average value of } C F \text { for } a \text { period }}{\text { The actual value of } C F \text { for } \text { a year }}=\frac{\frac{\sum_{k=1}^{N s} W_{k, j} \sum_{j=1}^{N c} \sum_{i=1}^{N y} C_{k, j, i}}{N y}}{C_{k, j, i}}
$$

where, $C_{k, j, i}$ are the values of a change factor (at the $i^{\text {th }}$ year, for a $j^{\text {th }} C F$ representing the $k^{\text {th }}$ stressor) at an individual meteorological station, or are the averaged meteorological time series for a region for the designated temporal domain. $N y, N s$ and $N c$ represents the number of years in the temporal domain, number of stressors and number of $C F S$ respectively. $W_{k, j}$ are the weights provided for the $j^{\text {th }} C F S$ representing $k^{\text {th }}$ stressor. The numerator in the Eq. 1 represents the average value of the $C F$ for a normal time-period. This period is subjective to the length of record available. $E I$ is the ratio, $E I=1$ means there is no exposure of the system due to climate variability and change. $E I$ deviating from $1(E I>1$ or $E I<1)$ indicates that the system is exposed to the climate stressors. The greater the deviation from 1, the greater the exposure. The $C F s$ are preferred in absolute scale to avoid negative values (e.g., temperature-based $C F$ are converted to Kelvin scale). See supplementary material-S.2 for further application of this equation and examples.

\subsection{Study region and data used}

Kansas was chosen as the study region because it is a part of the bread basket of the United States (Tubiello et al. 2002). It produces approximately $16 \%$ of the U.S. wheat crop (it was the top-producing state 9 of the last 10 years) and $50 \%$ of U.S. grain sorghum (USDA-NASS 2006). Approximately $90 \%$ of the area of Kansas is farmland (pasture and crops), and the state has the second highest area under cropland of all U.S. states. Only about $10 \%$ of the cropland is irrigated, indicating that much of Kansas' crop production is dependent on rainfall.

Daily rainfall and air temperature (maximum, minimum and average or $\mathrm{T}_{\max }, \mathrm{T}_{\min }, \mathrm{T}_{\mathrm{avg}}$ ) data from 23 centennial weather stations across Kansas were downloaded from the High Plains Regional Climate Center (Anandhi et al. 2013a). The station details are provided in Fig. 1a and Table S.2, respectively. The records extended from the late 1800 s for a few stations, but many observations began in the early 1900s; consequently, the start dates of the records are different but the end dates are the same (2009). The records were selected to cover non-overlapping 30-year timespans backward from 2009. The four time periods are through 1920, 1921-1950, 1951-1980, and 1981-2009. These stations were selected for their long-term data quality based on criteria such as consistent observation times, low potential for heat-island bias, and other quality assessments (Easterling et al. 1999; Robeson 2002).

\section{Results}

\subsection{System's approach to estimate exposure of agricultural production to climate change and variability}

A few studies have used a system's approach to address exposure while addressing vulnerability assessments in general (Gallopín 2006) and agricultural water resources in particular 
(Bär et al. 2015). This study uses a system's approach to estimate the exposure of agricultural production to climate change and variability (Fig. 1b). In this approach, an agricultural production is the system (represented as oval in Fig. 1b). This has internal processes (symbolized as spiral in Fig. 1b). Agricultural production system is considered a complex system which utilizes multiple resources (e.g. water, fertilizer) and provides multiple ecosystem services (e.g. food, climate change mitigation) (Zhang et al. 2007). When the agricultural production system is exposed to stressors (represented as dotted stars in Fig. 1b) they are considered a complex system. In this study, climate change and variability are the stressors which are represented using their characteristics such as type, magnitude, intensity; speed etc. Also, complex systems have characteristics (such as self-organization, emergence, chaos, and non-linearity) and operate at a wide range of spatial and temporal scales with many multi-scale interactions (Slingo et al. 2009; Hopkins et al. 2011). In this study, the characteristics of the complex system are represented using indicator-based approaches calculated from climate stressors and CFs. For example, crop failure temperature and yield decreases can be used as indicators to relate the characteristics of climate change/variability and agricultural production systems under stress. The advantages of using indicators were discussed in section 2.2. In general, the arrows in Fig. 1b show the direction of flow. There are two sets of arrow in Fig.1b (thin and bold arrows). The flow of resources into and from the agricultural production system is represented by arrows in oval (thin arrow in Fig. 1b). These thin arrows are in both directions, illustrating the exchanges of the system with its external environment. The bold arrows in the Fig. $1 \mathrm{~b}$ show the direction of the flow of processes in exposure estimations. They also represent the direction in which time moves in the figure.

\subsection{Flowchart to estimate $E I$}

The following steps, summarized in the flowchart (Fig. 1c), are recommended for an indicatorbased approach to estimate the exposure of agriculture to climate change and variability.

Step-1: Choose the study region: The scale component is important because agriculture can be analyzed at multiple scales (Bryant et al. 2000). The region could be based on physical or administrative boundaries (e.g., plot, field, county, state, country, continent, globe), and/or based on climate (e.g., point, climate zone), and/or based on hydrology (e.g., watershed, river basin).

Step-2: Identify the agricultural crops grown in the study region and select the crop(s) to assess. If there are several crops in a study region and the different crops have different tolerance /vulnerability for temperatures, then the flowchart to calculate an EI could be followed for each crop or for the most vulnerable crop in the region or a combination of crops.

Step-3: Identify and select the stressors: Rainfall variability, high and low temperature stress, drought, and floods were the most common stressors used in estimating EI (Table S.1). The other stressors used in the literature are potential evapotranspiration and growing season length (e.g., a function of frost-free period, length or timing of rainy season). Locationspecific stressors may also include cyclones, landslides, sea-level rise, cloud bursts, and hailstorms (Table S.1).

Step-4: Identify and select $C F(\mathrm{~s})$ : One or more climate variable can be identified as stressors. When multiple stressors are selected, each stressor can have one or more $C F \mathrm{~s}$. $C F$ s can represent mean and/or extreme values of the stressor and/or natural disasters that affect agriculture. 
From the pool of identified climate stressors, select one or more $C F$ for each stressor based on data availability and relevance. Climate factors from multiple data sources (e.g., measurement and model) also can be used to estimate $E I$.

Step-5: Decide on the period of interest (start/end dates and time of the year), which will depend on the study region, the chosen $\operatorname{crop}(\mathrm{s})$, the stressor(s), $C F(\mathrm{~s})$, and data sources. For example, measured monthly rainfall may be available for longer time periods than daily or sub-daily rainfall. Similarly, measured rainfall is available for longer time periods than rainfall obtained from radar or satellite data. After the start and end dates are chosen, select the time of year, which can be the entire year or the growing season or the time period during which crop productivity is most affected. It can vary with the region, its agriculture, and the data source. Growing season was commonly used in the literature along with the length of measured rainfall/temperature record as the start/end date. Some information on estimating seasons can be found in Anandhi (2010) and Anandhi et al. (2013a, b).

Step-6: Select an aggregation method. When multiple $C F$ s are used, an aggregation method must be selected to estimate $E I$, but this is not required in the case of single stressor-single $C F$ combination.

The flowchart for Kansas case study area demonstrate the different steps (briefly below and elaborated in S.3 in supplementary material).

Step 1: Choose the study region: Kansas.

Step 2: Identify and select the crops: Identified crops: sorghum, corn, soybean, and wheat. Selected crops: corn, sorghum and soybean.

Step 3: Identify and select the stressors: Identified stressors: rainfall, maximum and minimum temperatures, hail, windstorms. Selected stressors: rainfall, maximum temperature, and minimum temperature.

Step 4: Select the $C F(\mathrm{~s})$ to estimate exposure: The selected $C F \mathrm{~s}$ : average rainfall and temperatures $\left(\mathrm{T}_{\max }, \mathrm{T}_{\min }, \mathrm{T}_{\mathrm{avg}}\right.$ ); failure (ceiling) temperatures (days $\geq 35^{\circ} \mathrm{C}$ ); optimum temperature range for vegetative productivity in a crop (days with $30-33^{\circ} \mathrm{C}$ ).

Step 5: The period of interest (start/end dates and time of the year): The start date for 100 years of data varied between 1890 and 1908; while for thirty year period are 1921, 1951, and 1981. The end dates for the time periods are 1920, 1950, 1980, and 2009. Time of year: growing season [May through October (Anandhi et al. (2013a, b)].

Step 6: Estimate and validate $E I$ : $C F$ s were aggregated using equal weights and $E I$ s were calculated using Eq. 1 (elaborated in S1). Validation: estimated EIs plotted with sorghum yield stressed by rainfall and temperatures.

\subsection{EI estimated using five approaches}

The differences in the estimates among the five approaches for Kansas illustrate the implications of the choices made in the various steps in the flowchart (Figs. S.1 and S.2). Using 23 centennial stations (climate stations with $>100$-year time series, boxplots) elicited spatial variability and the implications of choosing the region (Step 1). The spread of 5-year moving averages time-series plot in Fig. S.1 and boxplot in each subplot (Fig. S.2) presented variability in exposure by station, location and by time-period. The variability in the estimated EIs for the 
different stressors [rainfall and temperatures $\left(T_{\max }, T_{\min }, T_{a v g}\right)$ ] can be observed by the $y$-axis of Figs. S.1, S.2. The implications of mean and extreme climate were highlighted by choosing $\mathrm{CF}$ s for a stressor to represent mean and extreme climate (Step 4). For instance average and minimum temperature EIs did not show a lot of variability in the time series and would be less useful. EIs based on extremes had more variability than those on mean, but the match to drought years was not that consistent. Choosing four different time periods and moving averages highlighted the variability in period of interest (Step 5). Combining stressors and CFs highlighted the variability among the five approaches (Step 6).

\section{Discussion}

\subsection{Climate stressors}

Identifying stressor(s) is an important component in estimating exposure (Fig. 1b). We recommend using region-specific climate stressors based on expert and local knowledge (e.g., through discussion with agronomists, breeders, plant physiologists, extension specialists and advisors, farmer experience), literature, or data. In some cases, additional region-specific stressors (e.g. landslides, sea-level-rise, cyclones) have been beneficial (Bhattacharya and Das 2007; Anh 2011). In addition, light, and humidity that control the growth and development of insects, pests, and diseases in agricultural crops (Esbjerg and Sigsgaard 2014) can also be stressors. However, data on climate variables such as solar radiation and humidity are sparse compared with rainfall and temperature (Anandhi et al. 2012; Anandhi et al. 2014).

In the absence of expert knowledge, literature or data on region-specific climate stressors, rainfall, and maximum and minimum temperature are recommended as climate stressors. The default data source is measured rainfall and/or temperature records, because they are readily available for long time periods worldwide. In situations where measurements or other data sources are not readily available, available global datasets which include global monthly precipitation datasets can be used.

\subsection{Climate factors $(C F s)$}

In the systems approach, we use CFs to represent the exposure of agricultural production to climate change and variability. As global temperatures rise, crops will increasingly begin to experience failure in traditional production regions, especially if climate variability increases or precipitation lessens. The standard deviation of precipitation and temperatures or their coefficients of variation $(\mathrm{CV})$ can be useful as $C F$ s. Failure temperature at which plant growth, production, and yield are severely affected (Hatfield et al. 2008) can also be used as $C F$ s. These critical temperatures are documented for the major crops in the world [Table 2.3 in Hatfield et al. (2008)] and can be applied in developing $C F$ s for vulnerability studies. Specific stages of growth (e.g., flowering, pollination, grain filling) are particularly sensitive to weather conditions and critical for final yield (Lavalle et al. 2009).

Some $C F$ s can be site specific. In tropical regions, heavy rainfall and strong winds are destructive to crops (Lansigan et al. 2000). In general, extreme high and low rainfall decreases yield (e.g. high rainfall prior to harvesting and low rainfall during critical crop growth stages) in many regions of the world. Indices such as the standard precipitation index (calculated from precipitation) and the PDSI [calculated from precipitation and temperature, Dai et al. (2004)] 
could be used as $C F$ s to represent drought and floods (Yan et al. 2013). These indices allow comparisons across time and regions. The potential evapotranspiration rate calculated from weather variablesalso could be applied as a $C F$ because it represents the integrated effects of changes in water availability and temperature on plant growth. Growing degree days (Anandhi 2016) and length or duration of warm/cold/wet/dry spells (Anandhi et al. 2016) during specific growth stages can also $C F$ s. Warm nights and hot or cold days could also be selected as $C F \mathrm{~s}$ because of their effects on crop yield (Prasad et al. 1999; Wheeler et al. 2000; Prasad et al. 2008). The other potential $C F$ s include mean temperature, mean precipitation, and number of days with precipitation due to their correlated with changes in insect phenology. These CFs impact insects relative to their date of first appearance of an insect, changes in insect generation time, number of generations per season, and geographical distribution (Esbjerg and Sigsgaard 2014). Specific temperature thresholds are available for very few insect pests or diseases [e.g., Fig. 1 in Yáñez-López et al. (2014)]. If available, they can be chosen as $C F$ s.

An aggregated $E I$ is calculated by combining multiple $C F$ s to represent single or multiple stressor(s). When aggregating CFs, all $C F s$ can be assigned equal or different weights (Baettig et al. 2007) based on expert judgment or statistical methods such as principal component analysis (Deressa et al. 2008; Simelton et al. 2009), correlation with past disaster events, or fuzzy logic (Bhattacharya and Das 2007).

To overcome issues of incommensurability when combining multiple indicators, normalization of data to a unitless scale and subsequent summation of the normalized data is common practice. This normalization/summation approach is problematic, however, because potentially important information regarding the relationships between the original variables are obscured (Abson et al. 2012). Although equal weight method is used in this study and is recommended for applications where no expert knowledge or data indicate a basis for assigning CFs different weights, the results in those situations can be highly biased by dominating $C F$ s.

\subsection{Kansas - case study}

Our results highlight the subjectivity of the exposure of agriculture to climate change and variability estimated using $E I$ s according to the choice of region, crop, stressor, $C F$, period of interest, and the approach used in estimating EIs. Climate for a region and crop and the choice of stressors and $C F s$ requires careful consideration; choosing the wrong stressors/CFs that can result in overrating or underrating the vulnerability of agriculture to climate change and variability. For example, in the case study, if only maximum temperature were chosen as the stressor and days $\geq 35^{\circ} \mathrm{C}$ were chosen as the $C F$, we would conclude that Kansas agriculture is very highly exposed to climate variability and change and is extremely vulnerable. In contrast, if only average temperature were chosen as the stressor and average temperature in the growing season were chosen as the $C F$, we could conclude that Kansas agriculture is not exposed to climate variability and change and is not vulnerable. We recommend estimating the EI using approaches 1-2 to select the most representative stressors and CFs. Then calculate the EI using Approach 5 by aggregating the selected stressors for vulnerability and risk assessments. Furthermore, the $E I$ s are affected by assigning equal weights to $C F$ s during aggregation (Figs. S.1 and S.2 h-i). The single $C F$ with the largest variation will dominate the other $C F$; conversely, the impact of the dominant $C F$ can be reduced by variation in other CFs (e.g. days with Tmax $\geq 35{ }^{\circ} \mathrm{C}$ dominate; Figs. S.1 and S.2 h-i). The domination of days with Tmax $\geq 35^{\circ} \mathrm{C}$ suppresses the stressor rainfall which impacts agricultural productivity in the region. Identification of the exposure of agriculture to climate change and variability is less subjective 
when chosen stressors/CFs involve characteristics that are representative and crucial to the survival or degradation of agro-ecosystems exposed to climate change and variability.

\subsection{Validation of $E I$}

Validation of the $E I$ can be carried out by comparing the estimated index with periods in which climate change and variability have stressed agricultural production systems. These periods can be obtained in a number of ways: (1) from earlier studies that refer to these periods as climate causing yield reduction; (2) using information from crop performance reports published by agricultural universities and research stations on yield reduction due to climate stress; (3) relating low crop yield to high exposure. In this study we used the first two methods. The droughts of the 1890s, 1930s, and 1950s have long served as benchmarks for severe and sustained drought in Kansas (Woodhouse et al. 2002). Although the spatial dimensions of these droughts were different, both the 1930s and 1950s had severe societal and ecological impacts on Kansas (Layzell and Evans 2012), thereby indicating high exposure and sensitivity to climate. The droughts were quantified using the PDSI (Dai et al. 2004). High exposure of agriculture to climate change and variability during those periods can be observed in our study based on high EIs when using temperature and precipitation as stressors. Most years with high exposure during 1957 to 2008 observed in this study coincide with the years reported as yieldlimiting for grain sorghum crop in this region [Table 1, Assefa et al. (2010)].

While comparing EIs with yield data over multi-decadal time periods, we have to be aware that major crop yields doubled in the second half of the 20th century (Khan and Hanjra 2009). Similar increases in grain sorghum, corn and soybean production were observed in the study region during the period as a result of hybrid improvement and adoption of better agronomic practices (Assefa and Staggenborg 2010; Assefa and Staggenborg 2011; Assefa et al. 2012; Rincker et al. 2014). Agricultural changes are further influenced by policy changes, urban development, and economic and social changes (Bryant et al. 2000). Such changes can mask the sensitivity of agriculture to climate change and variability. In general, it is difficult to separate climate effects from those of improved agricultural technologies when applying historic crop yields in an analysis (Lavalle et al. 2009).

\section{Summary}

In this paper, we used the system's approach to represent exposure of crop production to climate stressors, and summarized index-based approaches to estimate EIs using a conceptual diagram and flowchart. Applying this flowchart to estimate EIs requires information about the region of study, its agriculture, the climate stressor(s), climate factor(s) $(C F)$, the period of interest, and the method of aggregation. The flowchart was applied to a case study in Kansas to better illustrate the steps; implications of the five approaches; subjectivity of stressor(s), $C F(\mathrm{~s})$, time periods, and study region when selecting an $E I$ for application to a particular system.

When possible, EIs should be developed using the most appropriate stressor(s), associated $C F(\mathrm{~s})$, and aggregation methods based on a detailed methodological analysis. A detailed study is suggested. However, such a detailed study is likely to be too cumbersome because of resource constraints or insufficient information to provide conclusive evidence about which stressor(s), $C F(\mathrm{~s})$ and aggregation methods to employ. In that case, this study recommends using rainfall and temperature as the default stressors, $C F(\mathrm{~s})$ representing the mean and 
extreme statistics as the default $C F \mathrm{~s}$, and equal weights to aggregate the $C F$ s for calculating $E I$. This can be used as a preliminary start for an area, but again it has to be stressed the expert knowledge about critical factors for crop production needs to be included. Our discussions include highlighting this uncertainty and recommendation of local knowledge.

This analysis will be useful for general policy options (such as investment in irrigation, water harvesting, and other natural resource conservation) for decreasing the risk of exposure of the farmers and increasing their adaptive capacity to climate change and variability. EI's developed following the conceptual model and the steps in the flowchart can help prioritize our future research on risk and adaptation.

Calculating EIs for projected future temperature and rainfall and other dimensions of vulnerability, such as sensitivity and adaptive capacity, are deferred for future work. For a later paper it would be of interest to compare the use of the methodology in the flowchart and the application of the conceptual model to multiple locations with contrasting conditions.

Acknowledgments This work was supported by the National Science Foundation under Award No. EPS0903806 and matching support from the State of Kansas through Kansas Technology Enterprise Corporation and the Funding provided by USDA to Project No. 2013-69002-23146 through the National Institute for Food and Agriculture's Agriculture and Food Research Initiative, Regional Approaches for Adaptation to and Mitigation of Climate Variability and Change. Thanks also to the two anonymous reviewers for their thorough and insightful reviews of this paper. This is contribution number 14-308-J from the Kansas Agricultural Experiment Station.

Open Access This article is distributed under the terms of the Creative Commons Attribution 4.0 International License (http://creativecommons.org/licenses/by/4.0/), which permits unrestricted use, distribution, and reproduction in any medium, provided you give appropriate credit to the original author(s) and the source, provide a link to the Creative Commons license, and indicate if changes were made.

\section{References}

Abson DJ, Dougill AJ, Stringer LC (2012) Using Principal Component Analysis for information-rich socioecological vulnerability mapping in Southern Africa. Appl Geogr 35(1):515-524

Adger WN, Agrawala S, Mirza MMQ, Conde C, O’Brien K, Pulhin J, Pulwarty R, Smit B, Takahashi K (2007) Assessment of adaptation practices, options, constraints and capacity In: Parry, M.L. Canziani, O.F., Palutikof, J.P., Hanson, C.E., van der Linden P.J., (eds.) Climate Change 2007.: Impacts, Adaptation and Vulnerability. Contribution of Working Group II to the Fourth Assessment Report of the Intergovernmental Panel on Climate Change. Cambridge University Press: Cambridge, pp. 719-743.: 717-743

Anandhi A (2010) Assessing impact of climate change on season length in Karnataka for IPCC SRES scenarios. J Earth Syst Sci 119:447-460. doi:10.1007/s12040-010-0034-5

Anandhi A (2016) Growing degree days-Ecosystem indicator for changing diurnal temperatures and their impact on corn growth stages in Kansas. Ecol Indic 61:149-158

Anandhi A, Srinivas V, Kumar DN, Nanjundiah RS (2012) Daily relative humidity projections in an Indian river basin for IPCC SRES scenarios. Theor Appl Climatol 108:85-104

Anandhi A, Perumal S, Gowda PH, Knapp M, Hutchinson S, Harrington Jr J, Murray L, Kirkham MB, Rice CW. 2013a. Long-term spatial and temporal trends in frost indices in Kansas, USA. Clim Chang, 120: 169-181.

Anandhi A, Zion MS, Gowda PH, Pierson DC, Lounsbury D, Frei A (2013b) Past and future changes in frost day indices in Catskill Mountain region of New York. Hydrol Process 27:3094-3104

Anandhi A, Srinivas V, Kumar DN, Nanjundiah RS, Gowda PH (2014) Climate change scenarios of surface solar radiation in data sparse regions: a case study in Malaprabha River Basin, India. Clim Res 59:259-270

Anandhi A, Hutchinson S, Harrington Jr J, Rahmani V, Kirkham MB, Charles W, Rice (2016) Changes in spatial and temporal trends in wet, dry, warm and cold spell length or duration indices in Kansas, USA. Intn J of Climatology, (in press)

Anh VT (2011) Mapping Climate Change Vulnerability Using CBMS Data: A Pilot in Vietnam PEP-CBMS Working Paper Series: 1-18

Antwi-Agyei P, Fraser ED, Dougill AJ, Stringer LC, Simelton E (2012) Mapping the vulnerability of crop production to drought in Ghana using rainfall, yield and socioeconomic data. Appl Geophys 32:324-334 
Assefa Y, Staggenborg SA (2010) Grain sorghum yield with hybrid advancement and changes in agronomic practices from 1957 through 2008. Agron J 102:703-706

Assefa Y, Staggenborg S (2011) Phenotypic changes in grain sorghum over the last five decades. J Agron Crop Sci 197:249-257

Assefa Y, Staggenborg SA, Prasad VP (2010) Grain sorghum water requirement and responses to drought stress: A review. Online Crop Management. doi:10.1094/CM-2010-1109-01-RV

Assefa Y, Roozeboom KL, Staggenborg SA, Du J (2012) Dryland and irrigated corn yield with climate, management, and hybrid changes from 1939 through 2009. Agron J 104:473-482

Babel MS, Pandey VP, Rivas AA, Wahid SM (2011) Indicator-based approach for assessing the vulnerability of freshwater resources in the Bagmati River basin, Nepal. Environ Manag 48:1044-1059

Baettig MB, Wild M, Imboden DM (2007) A climate change index: Where climate change may be most prominent in the 21st century. Geophys Res Lett 34:L01705

Bär R, Rouholahnejad E, Rahman K, Abbaspour K, Lehmann A (2015) Climate change and agricultural water resources: A vulnerability assessment of the Black Sea catchment. Environ Sci Pol 46:57-69

Bhattacharya S, Das A (2007) Vulnerability to Drought, Cyclones and Floods in India. 1-39

Bryant C, Smit B, Brklacich M, Johnston T, Smithers J, Chjotti Q, Singh B (2000) Adaptation in Canadian Agriculture to Climatic Variability and Change. Clim Chang 45:181-201. doi:10.1023/a:1005653320241

Challinor AJ, Simelton ES, Fraser ED, Hemming D, Collins M (2010) Increased crop failure due to climate change: assessing adaptation options using models and socio-economic data for wheat in China. Environ Res Lett 5:034012

Dai A, Trenberth KE, Qian T (2004) A global dataset of Palmer Drought Severity Index for 1870-2002: Relationship with soil moisture and effects of surface warming. J Hydrometeorol 5:1117-1130

Deressa T, Hassan RM, Ringler C (2008) Measuring Ethiopian farmers' vulnerability to climate change across regional states. Intl Food Policy Res Inst

Dong Y, Chen H, Gu X, Wang J, Cui B (2012) Assessing and mapping crop vulnerability due to sudden cooling using time series satellite data. In: Geoscience and Remote Sensing Symposium (IGARSS), 2012 I.E. International, IEEE, pp: 2990-2993

Easterling DR, Karl TR, Lawrimore JH, Del Greco SA (1999) United States Historical Climatology Network Daily Temperature, Precipitation, and Snow Data for 1871-1997, ORNL/CDIAC-118, NDP-070. Carbon Dioxide Information Analysis Center, Oak Ridge National Laboratory, U.S. Department of Energy

Esbjerg P, Sigsgaard L (2014) Phenology and pest status of Agrotis segetum in a changing climate. Crop Prot 62: 64-71. doi:10.1016/j.cropro.2014.04.003

Fraser ED, Mabee W, Slaymaker O (2003) Mutual vulnerability, mutual dependence: The reflexive relation between human society and the environment. Glob Environ Chang 13:137-144

Fraser ED, Simelton E, Termansen M, Gosling SN, South A (2013) "Vulnerability hotspots": Integrating socioeconomic and hydrological models to identify where cereal production may decline in the future due to climate change induced drought. Agric For Meteorol 170:195-205

Gallopín GC (2006) Linkages between vulnerability, resilience, and adaptive capacity. Glob Environ Chang 16: 293-303

Gbetibouo GA, Ringler C, Hassan R (2010) Vulnerability of the South African farming sector to climate change and variability: an indicator approach. In: Natural Resources Forum, Wiley Online Library, pp: 175-187

Gerland P, Raftery AE, Ševčíková H, Li N, Gu D, Spoorenberg T, Alkema L, Fosdick BK, Chunn J, Lalic N (2014) World population stabilization unlikely this century. Science 346:234-237

Hatfield J, Boote K, Fay P, Hahn L, Izaurralde C, Kimball B, Mader T, Morgan J, Ort D, Polley W (2008) Agriculture. The effects of climate change on agriculture, land resources, water resources, and biodiversity in the United States. US Climate Change Science Program and the Subcommittee on Global Change Res., Washington, DC. 362 pp

Heltberg R, Bonch-Osmolovskiy M (2011) Mapping vulnerability to climate change, Policy Research Working Paper 5554. Washington, DC: World Bank: $19 \mathrm{pp}$

Hopkins TS, Bailly D, Støttrup J (2011) A systems approach framework for coastal zones. Ecol Soc 16(4):25

Horlings L, Marsden T (2011) Towards the real green revolution? Exploring the conceptual dimensions of a new ecological modernisation of agriculture that could 'feed the world'. Glob Environ Chang 21:441-452

Jackson L, Haden VR, Wheeler SM, Hollander AD, Perlman J, O'Geen T, Mehta VK, Clark V, Williams J, Thrupp A (2012) Vulnerability and Adaptation to Climate Change in California Agriculture. California Energy Commission. Publication number: CEC-500-2012-031

Kadir T, Mazur L, Milanes C, Randles K, (eds. \& comps) (2013) Indicators of Climate Change in California. Office of Environmental Health Hazard Assessment, California. Available at: http://oehha.ca.gov/multimedia/epic/ pdf/ClimateChangeIndicatorsReport2013.pdf (Accessed 21 Jan 2014): 228 pp

Khan S, Hanjra MA (2009) Footprints of water and energy inputs in food production-Global perspectives. Food Policy 34:130-140 
Lansigan F, De Los SW, Coladilla J (2000) Agronomic impacts of climate variability on rice production in the Philippines. Agric Ecosyst Environ 82:129-137

Lavalle C, Micale F, Houston TD, Camia A, Hiederer R, Lazar C, Conte C, Amatulli G, Genovese G (2009) Climate change in Europe. 3. Impact on agriculture and forestry. A review. Agron Sustain Dev 29:433-446

Layzell AL, Evans CS (2012) A thousand years of drought and climatic variability in Kansas-Implications for water resources management. Kansas Geological Survey, Open-File Report, 23 p., http:/www.kgs.ku.edu/ Hydro/Publications/2012/OFR12 18/index.html

Luers AL, Lobell DB, Sklar LS, Addams CL, Matson PA (2003) A method for quantifying vulnerability, applied to the agricultural system of the Yaqui Valley, Mexico. Glob Environ Chang 13:255-267

McCarthy JJ, Canziani OF, Leary NA, Dokken DJ, White KS (2001) Contribution of working group II to the third assessment report of the intergovernmental panel on climate change (IPCC). Contribution of Working Group II to the Third Assessment Report of the Intergovernmental Panel on Climate Change (IPCC) Cambridge University Press, London, UK p 1000

O’Brien K, Leichenko R, Kelkar U, Venema H, Aandahl G, Tompkins H, Javed A, Bhadwal S, Barg S, Nygaard L (2004a) Mapping vulnerability to multiple stressors: climate change and globalization in India. Glob Environ Chang 14:303-313

O’Brien K, Sygna L, Haugen JE (2004b) Vulnerable or resilient? A multi-scale assessment of climate impacts and vulnerability in Norway. Clim Chang 64:193-225

Oppenheimer M, Campos M, Warren R, Birkmann J, Luber G, O’Neill B, Takahashi K (2014) Chapter 19. Emergent Risks and Key Vulnerabilities. Climate Change 2014: Impacts, Adaptation, and Vulnerability (Retrieved from IPCC Working Group 2 website: http://ipcc-wg2.gov/AR5/): 1039-1099

Pandey R, Jha S (2012) Climate vulnerability index-measure of climate change vulnerability to communities: a case of rural Lower Himalaya, India. Mitig Adapt Strateg Glob Chang 17:487-506

Prasad PV, Craufurd P, Summerfield R (1999) Fruit number in relation to pollen production and viability in groundnut exposed to short episodes of heat stress. Ann Bot 84:381-386

Prasad P, Pisipati S, Ristic Z, Bukovnik U, Fritz A (2008) Impact of nighttime temperature on physiology and growth of spring wheat. Crop Sci 48:2372-2380

Rickards L, Howden S (2012) Transformational adaptation: agriculture and climate change. Crop and Pasture Science 63:240-250

Rincker K, Nelson R, Specht J, Sleper D, Cary T, Cianzio SR, Casteel S, Conley S, Chen P, Davis V (2014) Genetic improvement of US soybean in Maturity Groups II, III, and IV. Crop Science 54(4):1419-1432

Robeson SM (2002) Increasing Growing-Season Length in Illinois during the 20th Century. Clim Chang 52:219238. doi:10.1023/a:1013088011223

Simelton E, Fraser ED, Termansen M, Forster PM, Dougill AJ (2009) Typologies of crop-drought vulnerability: an empirical analysis of the socio-economic factors that influence the sensitivity and resilience to drought of three major food crops in China (1961-2001). Environ Sci Pol 12:438-452

Slingo J, Bates K, Nikiforakis N, Piggott M, Roberts M, Shaffrey L, Stevens I, Vidale PL, Weller H (2009) Developing the next-generation climate system models: challenges and achievements. Philos Trans R Soc A Math Phys Eng Sci 367:815-831

Tscharntke T, Clough Y, Wanger TC, Jackson L, Motzke I, Perfecto I, Vandermeer J, Whitbread A (2012) Global food security, biodiversity conservation and the future of agricultural intensification. Biol Conserv 151:53-59

Tubiello F, Rosenzweig C, Goldberg R, Jagtap S, Jones J (2002) Effects of climate change on US crop production: simulation results using two different GCM scenarios. Part I: Wheat, potato, maize, and citrus. Clim Res 20:259-270

USDA-NASS (2006) Agricultural statistics data base. Available at www.nass.usda.gov/Data_and_Statistics/Quick Stats/index. asp (verified 22 Oct. 2007). USDA-National Agricultural Statistics Service, Washington, DC

Walthall CL (2012) Climate change and agriculture in the United States: Effects and adaptation. USDA Technical Bulletin 1935:1-186

Wheeler TR, Craufurd PQ, Ellis RH, Porter JR, Vara PP (2000) Temperature variability and the yield of annual crops. Agric Ecosyst Environ 82:159-167

Woodhouse CA, Lukas JJ, Brown PM (2002) Drought in the western Great Plains, 1845-56: Impacts and implications. Bull Am Meteorol Soc 83:1485-1493

Yan D, Wu D, Huang R, Wang L, Yang G (2013) Drought evolution characteristics and precipitation intensity changes during alternating dry-wet changes in the Huang-Huai-Hai River basin. Hydrol Earth Syst Sci Discuss 10:2665-2696

Yáñez-López R, Torres-Pacheco I, Guevara-González R, Hernández-Zul M, Quijano-Carranza J, Rico-García E (2014) The effect of climate change on plant diseases. Afr J Biotechnol 11:2417-2428

Zhang W, Ricketts TH, Kremen C, Carney K, Swinton SM (2007) Ecosystem services and dis-services to agriculture. Ecol Econ 64:253-260 